\title{
Preventive and Therapeutic Effects of Anisakis simplex Larval Protein in a Mouse Model of Crohn'S Disease
}

\author{
Hee-Jae Cha, Mee Sun Ock \\ Department of Parasitology and Genetics, College of Medicine, Kosin University, Busan, Korea
}

\section{아니사키스 유충 유래 단백질의 크론병 예방 및 치료 효과}

차희재·옥미선

\section{고신대학교 의과대학 기생충학·유전학교실}

Objectives: Some helminths have been known to have a treatment effect in inflammatory bowel diseases, including Crohn's disease (CD); however, live parasite therapy can cause unwanted side effects. To develop a safe therapeutic, we investigated the preventive or therapeutic potential of proteins from the third stage larva of $A$. simplex in a mouse model. We also analyzed the cytokine profile from splenic and mesenteric lymph node lymphocytes to elucidate the underlying immunological mechanism.

Methods: CD was induced in mice with DSS, and the effect of an A. simplex larval protein on CD was assessed. A change in body weight and DAI (disease activity index) were observed in mice. The expression levels of cytokines from mesenteric lymph nodes (MLN) compared to splenic lymphocytes were measured with ELISA.

Results: Peritoneal administration of preventive and therapeutic A. simplex larval proteins attenuated DSS-induced CD by a reduction of the DAI and weight loss. A shortening of colon length was more definitely observed in the therapeutic group than in the preventive group. The cytokine expression levels were more obvious in lymphocytes from mesenteric lymph nodes than from splenic lymphocytes.

Conclusions: Taken together, these results suggest that $A$. simplex proteins can change cytokine profiles and may have a preventive effect in DSS-induced CD mice.

Key Words: Anisakis simplex, Crohn's disease, Cytokine, Prevention

Inflammatory bowel diseases (IBD) such as Crohn's disease (CD) are chronic inflammatory disorders of the intestine. Although the pathogenesis of IBD remains unknown, it is now considered to be a multifactorial disease that involves both genetic and environmental factors. The hygiene hypothesis (Strachan, 1989) contends that infants and children who lack exposure to infectious agents, symbiotic microorganisms, and parasites are more susceptible to allergic diseases by suppressing the natural development of the immune system. ${ }^{1}$ The high prevalence of allergic diseases in developed countries compared to less developed countries strongly supports the theory of the "hygiene hypothesis." Improved hygiene has been considered to alter the balance between type 1 (Th1) and type 2 (Th2) immune responses due to
Corresponding Author: Mee Sun Ock, Department of Parasitology and Genetics, College of Medicine, Kosin University, 262 Kamchunro Seogu, Busan, 602-703, Korea

TEL: +82-51-990-6424 FAX: +82-51-990-3081 E-mail: sunnyock@kosin.ac.kr
Received: March 7, 2013

Revised: April 11, 2013

Accepted: April 24, 2013 
a failure of immune regulation resulting in allergymediated Th2 responses. ${ }^{2}$ In the absence of Th1polarizing stimuli in childhood, mucosal immune responses fail to overcome their inherent Th2 bias and instead become slanted in the direction of allergy later in life. Helminths can also interact with both innate and adoptive immunity in the host and the resulting stimulation of a regulatory immune response. $^{3}$ Thus, exposure to helminths may help prevent or even ameliorate Crohn's disease.

Helminth therapies against IBD are being tried with various parasites. Summers et al. (2006) have successfully utilized the pig whipworm (Trichuris suis) in the treatment of patients with active Crohn's disease. ${ }^{4}$ Mortimer et al. (2006) also found that infection with Necator americanus larvae is promising for use in preliminary clinical therapeutic trials of asthma. ${ }^{5}$

However, helminth therapies have raised some concerns about the safety of living parasites. T. suis larvae can wander aimlessly, escaping from the gut of humans. ${ }^{6}$ Hsu et al. (2005) were also concerned about the detrimental effects of treatment with $T$. suis ova in nonresponsive patients. ${ }^{7}$

Therefore, identification and characterization of immunologically active proteins from helminths might ensure safety and overcome the revulsion to this therapy, as some patients are reluctant to ingest living parasites.

Anisakis simplex excretory-secretory protein was proven to induce the production of proinflammatory cytokines and chemokines from a mouse lung epithelial cell line and primary lung epithelial cells. ${ }^{8}$ Further, the recombinant MIFs (macrophage migratory inhibition factor) from $A$. simplex third stage larvae suppressed allergic airway inflammation by increasing TGF- $\beta$ and IL-10. ${ }^{9}$ These reports imply that $A$. simplex-derived proteins induce cytokines and can have a beneficial effect against CD.

The aim of this study was to investigate whether crude extract and ES product from $A$. simplex third stage larvae have a preventive or therapeutic potential in DSS-induced CD mice. We also examined the underlying immunological mechanism of the beneficial effect of $A$. simplex proteins by analyzing the cytokine profile of splenic and mesenteric lymph node lymphocytes.

\section{MATERIALS AND METHODS}

\section{Mice}

Eight-week-old female C57BL/6 mice were purchased from Hyochang Science (Daegu, Korea). The mice were housed in a laminar flow cabinet throughout the experiments and were allowed free access to standard rodent chow. All animal studies were approved by the Animal Care and Use Committee of the Kosin University College of Medicine.

\section{Anisakis simplex larvae collection and excretory-secretory product and so- matic product preparation}

A. simplex L3 larvae were collected manually from the viscera, flesh, and body cavities of naturally infected mackerels (Scomber japonicus) and thoroughly washed with PBS (phosphate buffered saline). The preparation of somatic product (SP) and excretory-secretory product (ES) from A. simplex L3 larvae was performed as described previously. ${ }^{10}$ Briefly, about $1 \mathrm{~g}$ (300 larvae) of larvae was frozen in liquid nitrogen and smashed by mortar. To extract the proper amounts of SP proteins, the protein extraction solution was added and stored on ice for 
30 min according to the manufacturer's instructions (PRO_PREP ${ }^{\mathrm{TM}}$, iNtRON Biotechnology, Seoul, Korea). The supernatant was collected after centrifugation at maximum speed for $10 \mathrm{~min}$ at $4^{\circ} \mathrm{C}$. The amount of protein was measured by the Bradford method. To prepare the ES product, Larvae were incubated in DMEM (Dulbecco's Modified Eagle Medium) with gentamycin $(150 \mathrm{mg} / \mathrm{mL})$ and vancomycin $(10 \mathrm{mg} / \mathrm{mL})$ at $0.5 \mathrm{~mL} /$ larva and $37^{\circ} \mathrm{C}$ for $48 \mathrm{hr}$. The media were collected and centrifuged at $2500 \mathrm{rpm}$ for $20 \mathrm{~min}$ and concentrated with Amicon stirred cells with a cut off molecular weight of less than 10,000 (Millipore Corp, Massachusetts, USA).

\section{Experimental groups of mice and $A$. simplex protein injection}

We divided the mice into 4 groups, which consisted of 8 mice in each group. One experimental group of mice (preventive group) was injected with SP and ES products intraperitoneally before DSS solution was administered. The other group of mice was first given DSS solution for 4 days and then treated with SP and ES product (therapeutic group). The amount of protein injected in both groups of mice was $10 \mu \mathrm{g}$ a day for 7 days. Mice were checked each day for morbidity, and their weights were recorded. The negative control group of mice received only drinking tap water. The positive control group was given DSS solution only.

\section{Induction and assessment of DSS- induced colitis}

In order to induce intestinal inflammation, mice were given a solution of drinking water containing 3\% DSS (36-50 kDa; MP Biomedicals, Santa Ana, CA, USA) for 7 days ad libitum. The DSS solution was replenished every other day, and at the end of the fourth day, the animals were sacrificed. The assessment of disease activity index (DAI) was carried out once a day. DAI was the combined score of weight loss (scored as: 0, none; 1, 1-5\%; 2, 5-10\%; 3, 10-20\%; 4, over 20\%), stool consistency (scored as: 0, well-formed pellets; 2, loose stools; 4, diarrhea) and bleeding (scored as: 0, negative hemoccult; 2, positive hemoccult; 4, rectal bleeding). The colons were removed and measured from $1 \mathrm{~cm}$ above the anus to the top of the cecum.

\section{Lymphocyte preparation and cytokine analysis}

After the mice were sacrificed, lymphocytes from their spleens and mesenteric lymph nodes (MLN) were isolated to determine the level of specific cytokines. The spleens and MLN were disrupted and treated with ACK hypotonic lysis solution (Sigma, Seoul, Korea) for 2 min at room temperature for RBC (red blood cell) lysis. RBC-depleted lymphocytes were filtered through $100 \mu \mathrm{m}$ mesh (Small Parts Inc., Seattle, WA, USA), and the cells were plated in wells at $5 \times 10^{6}$ cells $/ \mathrm{mL}$ in RPMI 1640 with 10\% fetal bovine serum (FBS) and penicillin / streptomycin. The plated cells were then incubated for $72 \mathrm{~h}$ at $37^{\circ} \mathrm{C}$ in $5 \% \mathrm{CO}_{2}$. After $72 \mathrm{~h}$ incubation, the supernatants were harvested. The cytokine levels, including IL-1 $\alpha$, IL- $1 \beta$, IL-2, and IFN $-\gamma$, were determined with ELISA in accordance with the manufacturer's instructions (eBioscience, R\&D Systems, Korea). The absorbance of the final reactant was determined at $450 \mathrm{~nm}$ using an ELISA plate reader.

\section{Statistical analysis}

Experiments were conducted at least in triplicate, and data are expressed as means \pm SD. Student's t-test was applied for comparison between groups. $P$ values of $<0.05$ were considered statistically significant in 
all experiments.

\section{RESULTS}

\section{A challenge with Anisakis simplex- derived protein can protect mice against DSS-induced colitis}

To evaluate the potential effects of $A$. simplexderived protein, the mice were treated with SP and ES products (10 $\mu \mathrm{g} /$ mouse, once a day) for 7 days before or after DSS administration. A remarkable weight loss of mice after DSS administration was observed. The body weight in the preventive group slowly increased until the $12^{\text {th }}$ day and decreased after that. This reduction was consistent with the DSS injection. In the therapeutic group, the body weight rapidly fell after DSS administration, but the mice gained weight along with injection of $A$. simplex protein (Fig. 1). The average body weight was higher in the preventive group than in the therapeutic group (18.3 $\mathrm{g} \pm 1.22,18.0 \mathrm{~g} \pm$ 1.14). The DAI decreased after 14 days in the preventive group, whereas it was

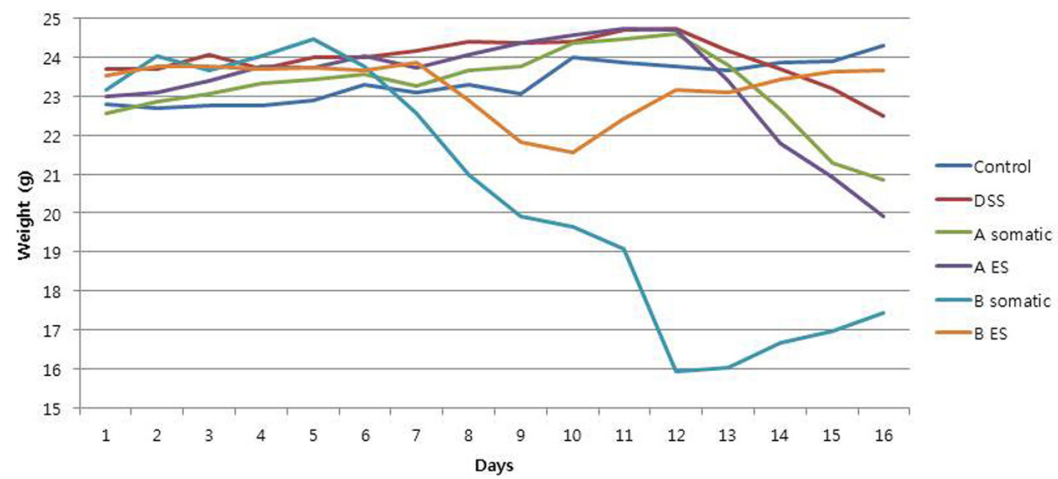

\begin{tabular}{|c|c|c|}
\hline $\mathrm{H}_{2} \mathrm{O}$ & $\mathrm{H}_{2} \mathrm{O}$ & control group \\
\hline $\mathrm{H}_{2} \mathrm{O}$ & DSS & DSS group \\
\hline SP & DSS & $S P+D S S$ group \\
\hline ES & DSS & ES + DSS group \\
\hline DSS & SP & DSS + SP group \\
\hline DSS & ES & D \\
\hline
\end{tabular}

Fig. 1. Changes in body weight in each group of mice. SP + DSS and ES + DSS groups are preventive groups; DSS + SP and DSS + ES groups are therapeutic groups. The average body weight was higher in the preventive groups than in the therapeutic groups.

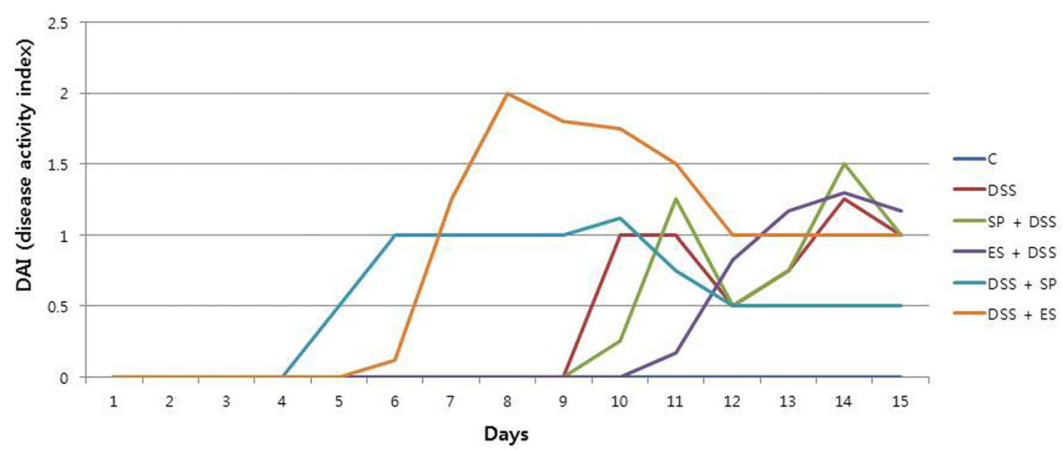

Fig. 2. DAl's were measured daily during the experimental period in each group of mice. SP + DSS and ES + DSS groups are preventive groups; DSS + SP and DSS + ES group are therapeutic groups. 
sustained in the therapeutic group (Fig. 2). The colon length of mice in the therapeutic and DSS groups was much shorter than in the preventive and negative control groups (Fig. 3). These findings imply that $A$. simplex protein injection resulted in a reduction of the DAI and maintenance of body weight and colon length, especially in the preventive group.

\section{Proteins from Anisakis simplex L3 can change the cytokine profile in DSS- treated mice}

The cytokine expression levels were obvious in lymphocytes from mesenteric lymph nodes compared to splenic lymphocytes (Fig. 4). The pro-inflammatory cytokines IL-1 $\alpha$ and IL-1 $\beta$ were highly increased in the MLN of the DSS-injected mice group. A decrease in IL-1 $\alpha$ was evident in the preventive group, while the expression level of $\mathrm{IL}^{-1} \beta$ dropped

(A)

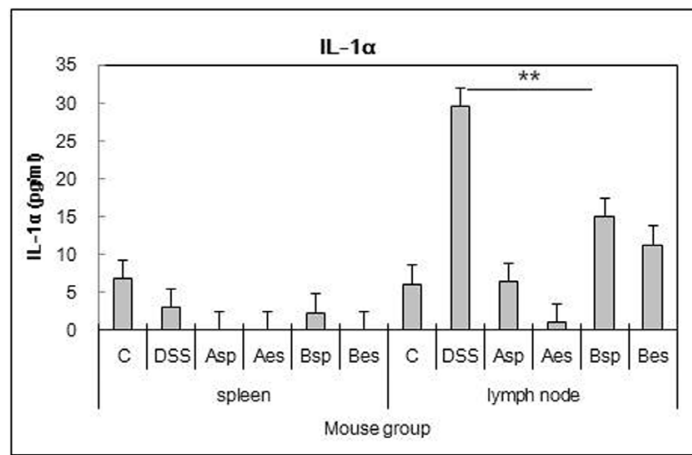

(C)

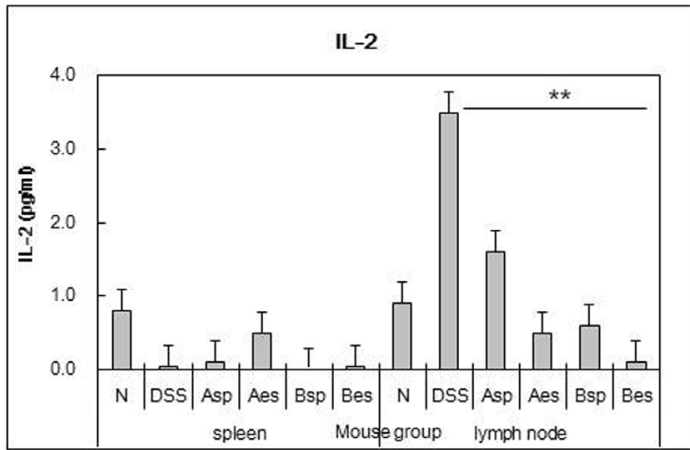

in both the preventive and therapeutic groups (Fig. 4A, B). These results indicate that $A$. simplex-derived

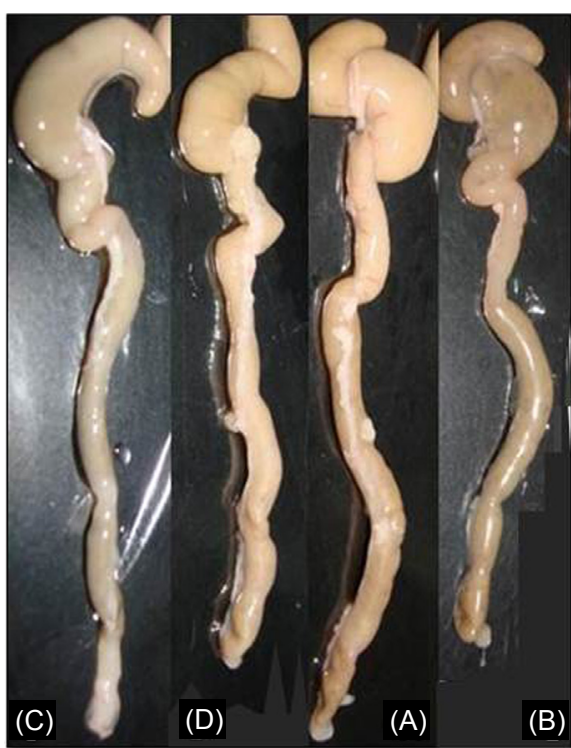

Fig. 3. The representative colon from each group of mice. (C) control group, (D) DSS-treated group, (A) preventive group, (B) therapeutic group. The colons of the mice in the preventive group maintained their original length.
(B)

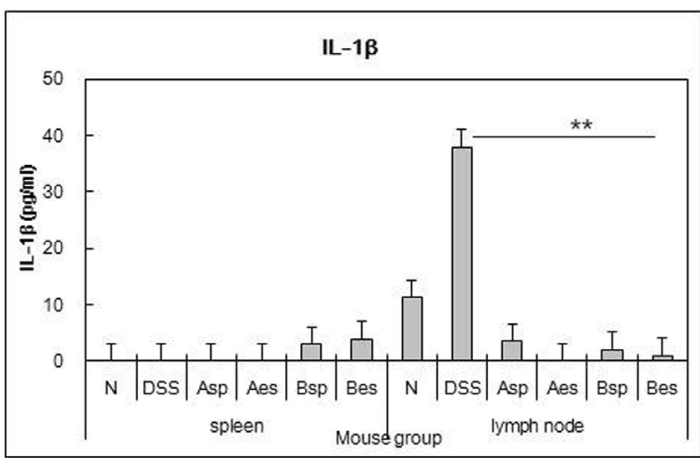

(D)

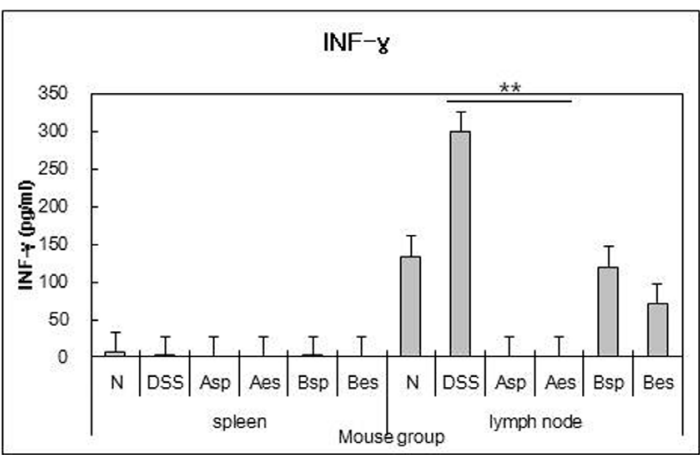

Fig. 4. Cytokine profile of splenic and lymph node lymphocytes. Expression levels of IL- $\alpha$ (A), IL-1 $\beta$ (B), IL-2 (C), and IFN- $\gamma$ (D) were measured with ELISA after administration of A. simplex protein. C; control, DSS; DSS only, Asp and Aes denotes preventive group injected with SP (somatic protein) and ES (excretory-secretory) protein. 
protein can suppress the expression of proinflammatory cytokines. In the case of IL-2, the decrease was noticeable in the therapeutic group, particularly by ES product (Fig. 4C). IFN $-\gamma$ was nearly unexpressed in the spleen, while the expression of IFN- $\gamma$ in MLN lymphocytes of the DSS group was significantly increased (Fig. 4D). The injection of SP and ES nullified the production of IFN $-\gamma$. This effect was more prominent in the preventive group. These results suggest that protein from $A$. simplex can alter the cytokine profile and improve the condition of mice suffering from DSS-induced colitis.

\section{DISCUSSION}

The cytokine profiles in IBD are the key pathophysiologic factors in determining the initiation and severity of the disease. In this work, we investigated whether Anisakis larval proteins can change the pattern of cytokine expression and have a preventive or therapeutic effect in a mouse CD model. We found that MLN lymphocytes have stronger responses than splenic lymphocytes. It was also revealed that Anisakis-derived proteins can mitigate the disease by decreasing proinflammatory cytokine production and maintaining the length of the colon. ES proteins induced a more robust inhibition of cytokine production compared to SP proteins. The expression of IL- $1 \alpha, \mathrm{IL}^{-1} \beta$, and IFN- $\gamma$ were significantly downregulated in the preventive groups, while the IL-2 level was considerably decreased in the therapeutic groups. It is therefore reasonable to deduce that $A$. simplex larval protein can be a potential agent for improving $\mathrm{CD}$ in a preventive manner.

$\mathrm{CD}$ has been characterized as a Th1 cytokinemediated disease accompanied by the production of interferon (IFN) $-\gamma .{ }^{11-12}$ Therefore, IFN $-\gamma$ was tried as a therapeutic agent for $\mathrm{CD}^{13-14}$ When we applied Anisakis proteins in a CD mouse model, the amount of IFN- $\gamma$ expression significantly reduced, especially in the preventive groups. IFN- $\gamma$ also affects downstream effector cells to induce the production of pro-inflammatory cytokines such as IL-1 $\beta$. The level of $\mathrm{IL}-1 \beta$ has more than tripled in the DSS group compared to the control group. The injection of Anisakis proteins lowered the level of IL-1 $\beta$ to below the level of the control group. The expression level of IL-1 $\alpha$ also decreased, although the reduction was less noticeable than for $\mathrm{IL}^{-1} \beta$. IL-2 showed a significant decrease in the therapeutic group, especially in the ES protein-injected group. These results show that $A$. simplex larval proteins can bring a favorable effect in a mouse model of $\mathrm{CD}$. This favorable effect was reaffirmed by comparing colon length between the mice of the DSS and proteininjected groups.

Many parasites proteins were proven to ameliorate IBD in human and animal models. Soluble proteins from Schistosoma mansoni and Ancylostoma caninum showed a therapeutic effect in a TNBS-induced colitis mouse model by decreasing IFN- $\gamma$ and IL-17 in colonic tissue and mesenteric lymph nodes. ${ }^{15}$ In addition, $T$. suis egg therapy has already successfully been tried in CD patients. ${ }^{16}$ Trichinella spiralis infection brought a similar protective effect in DNBS-induced colitis mice, which was associated with an IFN- $\gamma$ and IL-12 decrease. ${ }^{17}$ These previous studies correspond with our result of a significant reduction of IFN $-\gamma$. This finding leads to the conclusion that helminth or helminth-derived proteins could be used in the treatment and prevention of IBD. 
In conclusion, $A$. simplex proteins can exert a treatment effect by decreasing proinflammatory cytokines and can be a candidate for shaping the human immune system. These trials can help us understand the mechanism of $\mathrm{CD}$ and provide a new insight for CD control.

\section{REFERENCES}

1. Strachan DP. Hay fever, hygiene, and household size. BMJ 1989;299:1259-60.

2. Yazdanbakhsh M, Kremsner PG, van Ree R. Allergy, parasites, and the hygiene hypothesis. Science. 2002;296:490-4.

3. Weinstock JV, Elliott DE. Helminths and the IBD hygiene hypothesis. Inflamm Bowel Dis 2009;15:128-33.

4. Summers RW, Elliott DE, Urban JF Jr, Thompson RA, Weinstock JV. Trichuris suis therapy for active ulcerative colitis: a randomized controlled trial. Gastroenterology 2005;128:82532.

5. Mortimer K, Brown A, Feary J, Jagger C, Lewis S, Antoniak M,et al. Dose-ranging study for trials of therapeutic infection with Necator americanus in humans. Am J Trop Med Hyg 2006;75:914-20.

6. Van Kruiningen HJ, West AB. Potential danger in the medical use of Trichuris suis for the treatment of inflammatory bowel disease. Inflamm Bowel Dis 2005;11:515.

7. Hsu S-J, Tseng P-H, Chen P-J. Trichuris suis therapy for ulcerative colitis: nonresponsive patients may need antihelminth therapy. Gastroenterology 2005;129:768-9.

8. Cho MK, Ahn SC, Kim DH, Yu HS. Parasite excretory-secretory proteins elicit TRIF dependent CXCL1 and IL-6 mediated allergic inflammation. Parasite Immunol 2010;32:354-60.

9. Park SK, Cho MK, Park HK, Lee KH, Lee SJ, Choi SH,et al. Macrophage migration inhibitory factor homologs of Anisakis simplex suppress Th2 response in allergic airway inflammation model via CD4+CD25+Foxp3+ T cell recruitment. J Immunol
2009;182:6907-14.

10. Kim J, Jo JO, Choi SH, Cho MK, Yu HS, Cha HJ,et al. Seroprevalence of antibodies against Anisakis simplex larvae among health-examined residents in three hospitals of southern parts of Korea. Korean J Parasitol 2011;49:139-44.

11. Breese E, Braegger CP, Corrigan CJ, Walker-Smith JA, MacDonald TT. Interleukin-2- and interferon-gamma-secreting $\mathrm{T}$ cells in normal and diseased human intestinal mucosa. Immunology 1993;78:127-31.

12. Fuss IJ, Neurath M, Boirivant M, Klein JS, de la Motte C, Strong SA,et al. Disparate CD4+ lamina propria (LP) lymphokine secretion profiles in inflammatory bowel disease. Crohn's disease LP cells manifest increased secretion of IFN-gamma, whereas ulcerative colitis LP cells manifest increased secretion of IL-5. J Immunol 1996;157:1261-70.

13. Hommes DW, Mikhajlova TL, Stoinov S, Stimac D, Vucelic B, Lonovics J,et al. Fontolizumab, a humanised anti-interferon gamma antibody, demonstrates safety and clinical activity in patients with moderate to severe Crohn's disease. Gut 2006;55:1131-7.

14. Reinisch W, Hommes DW, Van Assche G, Colombel JF, Gendre JP, Oldenburg B,et al. A dose escalating, placebo controlled, double blind, single dose and multidose, safety and tolerability study of fontolizumab, a humanised anti-interferon gamma antibody, in patients with moderate to severe Crohn's disease. Gut 2006;55:1138-44.

15. Ruyssers NE, De Winter BY, De Man JG, Loukas A, Pearson MS, Weinstock JV,et al. Therapeutic potential of helminth soluble proteins in TNBS-induced colitis in mice. Inflamm Bowel Dis 2009;15:491-500.

16. Summers RW, Elliott DE, Urban JF Jr, Thompson R, Weinstock JV. Trichuris suis therapy in Crohn's disease. Gut 2005;54:8790.

17. Khan WI, Blennerhasset PA, Varghese AK, Chowdhury SK, Omsted P, Deng $\mathrm{Y}$, et al. Intestinal nematode infection ameliorates experimental colitis in mice. Infect Immun 2002; 70:5931-7. 